University, Eye Care Centre, 1278 Tower Road, Halifax, NS, Canada B3H 2Y9; nicolela@dal.ca Competing interests: None declared.

\section{REFERENCES}

1 Leske MC, Heij A, Hussein M, et al. Factors for glaucoma progression and the effect of treatment:
the early manifest glaucoma trial. Arch Ophthalmol 2003;121:48-56.

2 Drance S, Anderson DR, Schulzer M. Risk factors for progression of visual field abnormalities in normal-tension glaucoma. Am J Ophthalmol 2001;131:699-708

3 Gordon MO, Beiser JA, Brandt JD, et al. The ocular hypertension treatment study: baseline factors that predict the onset of primary open-angle glaucoma. Arch Ophthalmol 2002;120:714-20.

4 Budenz DL, Anderson DR, Feuer WJ, et al. Detection and prognostic significance of optic disc hemorrhages during the ocular hypertension treatment study. Ophthalmology 2006;113:2137-430.

5 Balarathnasingam C, Morgan WH, Hazelton ML, et al. Value of retinal vein pulsation characteristics in predicting increased optic disc excavation. Br J Opthalmol 2007;91:441-4.

6 Morgan WH, Hazelton ML, Azar SL, et al. Retinal venous pulsation in glaucoma and glaucoma suspects. Ophthalmology 2004; 111:1489-94.

7 Morgan WH, Balaratnasingam C, Hazelton ML, et al. The force required to induce hemivein pulsation is associated with the site of maximum field loss in glaucoma. Invest Ophthalmol Vis $\mathrm{Sci}$ 2005;46: 1307-12.

8 Jonas JB. Retinal venous pulsation and glaucoma. Ophthalmology 2005; 1 12:948-9.

9 Meyer-Schwickerath R, Kleinwachter T, Firsching R, et al. Central retinal venous oufflow pressure. Graefes Arch Clin Exp Ophthalmol 1995;233:783-8.

10 Jacks AS, Miller NR. Spontaneous retinal venous pulsation: aetiology and significance. I Neurol Neurosurg Psychiatry 2003;74:7-9.

11 Levine DN. Spontaneous pulsation of the retinal veins. Microvasc Res 1998;56:154-165.

12 Dielemans I, Vingerling JR, Algra D, et al. Primary open-angle glaucoma, intraocular pressure, and systemic blood pressure in the general elderly population. The Rotterdam Study. Ophthalmology 1995; 102:54-60.

13 Mitchell P, Lee AJ, Rochtchina E, et al. Open-angle glaucoma and systemic hypertension: the blue mountains eye study. J Glaucoma 2004;13:319-26.

14 Nicolela MT, Drance SM, Rankin SJ, et al. Color Doppler imaging in patients with asymmetric glaucoma and unilateral visual field loss. Am J Ophthalmol 1996;121:502-10.
15 Butt Z, O'Brien C, McKillop G, et al. Color Doppler imaging in untreated high- and normal-pressure open-angle glaucoma. Invest Ophthalmol Vis Sci 1997:38:690-6.

16 Sperduto RD, Hiller R, Chew E, et al. Risk factors for hemiretinal vein occlusion: comparison with risk factors for central and branch retinal vein occlusion: the eye disease case-control study. Ophthalmology 1998;105:765-71.

17 Risk factors for central retinal vein occlusion. The eye disease case-control study group. Arch Ophthalmol 1996; 114:545-54.

18 Soares AS, Artes PH, Andreou P, et al. Factors associated with optic disc hemorrhages in glaucoma. Ophthalmology 2004;111:1653-57.

19 Quigley HA, Addicks EM. Chronic experimental glaucoma in primates. II. Effect of extended intraocular pressure elevation on optic nerve head and axonal transport. Invest Ophthalmol Vis Sci 1980;19:137-52

20 Quigley HA, Hohman RM, Addicks EM, et al. Blood vessels of the glaucomatous optic disc in experimental and human eyes. Invest Ophthalmol Vis Sci 1984;25:918-31.

21 Burgoyne CF, Downs JC, Bellezza AJ, et al. The optic nerve head as a biomechanical structure: a new paradigm for understanding the role of IOPrelated stress and strain in the pathophysiology of glaucomatous optic nerve head damage. Prog Retin Eye Res 2005;24:39-73.

\title{
All in the timing
}

\section{Bryan J Winn}

\section{$\mathrm{mfVEP}$ as a measure of perimetry}

n this issue of the $B J O$, the paper by Semela et al ${ }^{1}$ (see page 445) reports on the characteristics of the multifocal visual evoked potential (mfVEP) in six cases of compressive optic neuropathy (CON) secondary to optic nerve meningiomas. The mfVEP can be thought of as an objective measure of perimetry. With the display used by Semela's group, the 60 sectors tested comprise about the same area of visual field as the Humphrey 24-2 standard automated perimetry (SAP) test. Unlike SAP, the mfVEP does not require the subject to consciously register and respond to stimuli but rather is generated by the electrical potentials evoked by the individual pattern-reversal stimuli at the primary visual cortex. ${ }^{2}$ The amplitudes of mfVEPs have been shown to correlate well with SAP in several optic neuropathies including ischaemic optic neuropathy (ION) and glaucoma..$^{2-8}$ It is not surprising that the mfVEP amplitudes in optic nerve meningiomas follow suit. This is in agreement with work by DaneshMeyer $e a^{9}{ }^{9}$ using the AccuMap system of mfVEP, demonstrating good amplitude correlation with SAP in CON due to pituitary lesions.
However, unlike the mfVEPs seen in ION and glaucoma, Semela et al demonstrate that CON mfVEPs have significant latency delays. ${ }^{10}{ }^{11}$ This is consistent with conventional VEP studies showing prolonged latencies in compressive neuropathies including those caused by chiasmal gliomas, orbital tumours and thyroid orbitopathy. ${ }^{12-17}$ Prolongations in latency have been attributed to disruptions of the saltatory conduction along the myelinated portion of ganglion cell axons and are the hallmark of demyelinating entities such as optic neuritis. ${ }^{78}$ Both mechanical and vascular mechanisms for CON have been proposed, and an experimental model of compressive peripheral neuropathy induced by a pneumatic tourniquet demonstrating anatomical disruption of the nodes of Ranvier and subsequent demyelination supports Semela et al's findings. ${ }^{17} 19$

Semela et al found that the latency delays occurred topographically at the interface between normal and abnormal regions of the visual field and could be seen in areas of visual field that test normal on SAP, as is shown in their cases 1 and 4 . Delays may not be seen inside the scotoma owing to the fact that the mfVEP amplitudes are typically so diminished in areas of significant field loss that information on timing in these sectors is lost. However, the delays seen outside the areas of field loss are perhaps more interesting. Do these delays represent early signs of compressive optic nerve dysfunction? Although potentially interesting, this is clinically irrelevant in cases of optic nerve meningiomas as most of the cases are diagnosed only after presenting with visual loss. However, if true, it could prove a useful method for diagnosing early compressive neuropathy in thyroid orbitopathy and pituitary adenomas.

Unlike ION and glaucoma, which typically are not associated with any recovery of visual field, CONs frequently will improve when the compression is relieved. What happens to the latency changes after surgery or radiation? Are the latency changes somehow linked to the ability of nerves for recovery? Studies documenting visual outcomes after either surgical or radiation decompression of CONs show that $40-47 \%$ improved, 33$40 \%$ remain stable and about $20 \%$ worsen. ${ }^{20}{ }^{21}$ Does the presence or absence of latency delays correlate with prognosis? It would be interesting to see how the mfVEPs and SAPs of Semela et al's six cases change after intervention.

Semela et al suggest monitoring changes in amplitude for evidence of progression or recovery of CON. This is good for modest visual field defects. We know, though, that mfVEP amplitudes can be completely wiped out when Humphrey visual field thresholds drop below $-6 \mathrm{~dB} .{ }^{22}$ Theoretically, a recovery from -20 to $-10 \mathrm{~dB}$ in a localised area 
could go unnoticed since the mfVEP might not have a detectable amplitude in either case. However, since the latency changes frequently occur at the perimeter of the field deficit, and if we posit that in the presence of normal amplitudes they may represent the earliest detectable damage, changes in latency could signal the subtlest progression or recovery of disease.

As with all theory and conjecture, validation or rejection by experimentation is required. Semela et al's findings invite several interesting questions on the significance and relevance of latency shifts in compressive neuropathies. It is easy to hypothesise about them, but only further experimentation will provide real answers.

Br J Ophthalmol 2007;91:406-407. doi: 10.1136/bjo.2006.108332

Correspondence to: Dr Bryan J Winn Department of Ophthalmology, UCSF Medical Center, 10 Koret Way, Room K301, San Francisco, CA 94143, USA;

bjw15@columbia.edu

Competing interests: None declared.

\section{REFERENCES}

Semela L, Yang E Bo, Thomas R H, et al. Multifocal visual evoked potential in unilateral compressive optic neuropathy $\mathrm{Br} J$ Ophthalmol 2007:91:445-8.

2 Hood DC, Greenstein VC. Multifocal VEP and ganglion cell damage: applications and limitations for the study of glaucoma. Prog Retin Eye Res 2003;22:201-51.

3 Goldberg I, Graham SL, Klistorner I. Multifocal objective perimetry in the detection of glaucomatous field loss. Am J Ophthalmol 2002;133:29-39.

4 Hood DC, Thienprasiddhi P, Greenstein VG, et al. Detecting early to mild glaucomatous damage: a comparison of the multifocal VEP and automated perimetry Invest Ophthalmol Vis Sci 2004:45:492-8.

5 Hood DC, Zhang X, Greenstein VC, et al. An interocular comparison of the multifocal VEP: a possible technique for detecting local damage to the optic nerve. Invest Ophthalmol Vis $\mathrm{Sci}$ 2000;41:1580-7.

6 Klistorner Al, Graham SL. Objective perimetry in glaucoma. Ophthalmology 2000;107:2283-99.

7 Hood DC, Odel JG, Winn BJ. The multifocal visual evoked potential. I Neuroophthalmol 2003;23:279-89.

8 Hood DC, Zhang X, Winn BJ. Detecting glaucomatous damage with multifocal visual evoked potentials: how can a monocular test work? J Glaucoma 2003;12:3-15.

9 Danesh-Meyer HV Carroll SC, Gaskin BJ, et al. Correlation of the multifocal visual evoked potentia and standard automated perimetry in compressive optic neuropathies. Invest Ophthalmol Vis Sci 2006;47:1458-63

10 Rodarte C, Hood DC, Yang EB, et al. The effects of glaucoma on the latency of the multifocal visual evoked potential. Br J Ophthalmol 2006:90:1132-6.

11 Odel JG, Rodarte C, Yang EB, et al. A quantitative measure of multifocal visual evoked potential latencies in ischemic optic neuropathy and optic neuritis. ARVO, 2005, Poster 642
12 Halliday AM, Halliday E, Kriss A, et al. The patternevoked potential in compression of the anterio visual pathways. Brain 1976;99:357-74.

13 Kupersmith MJ, Siegel IM, Carr RE, et al. Visual evoked potentials in chiasmal gliomas in four adults. Arch Neurol 1981;38:362-5.

14 Tsaloumas MD, Good PA, Burdon MA, ef al. Flash and pattern visual evoked potentials in the diagnosis and monitoring of dysthyroid optic neuropathy. Eye 1994:8(Pt 6):638-45.

15 Setala K, Raitta C, Valimaki $M$, et al. The value of visual evoked potentials in optic neuropathy of Graves' disease. J Endocrinol Invest 1992:15:821-6.

16 Bobak DA, Washburn RG, Frank MM. Visual evoked potentials to multiple temporal frequencies. Use in the differential diagnosis of optic neuropathy. Arch Ophthalmol 1988;106:936-40.

17 Janaky M, Benedek G. Visual evoked potentials during the early phase of optic nerve compression in the orbital cavity. Doc Ophthalmol 1992;81:197-208

18 Hood DC, Odel JG, Zhang X. Tracking the recovery of local optic nerve function after optic neuritis: a multifocal VEP study. Invest Ophthalmol Vis Sci 2000;41:4032-8

19 Ochoa J, Fowler TJ, Gilliatt RW. Anatomical changes in peripheral nerves compressed by a pneumatic tourniquet. J Anat 1972;113(P 3):433-55.

20 Sleep TJ, Hodgkins PR, Honeybul S, et al. Visual function following neurosurgical optic nerve decompression for compressive optic neuropathy. Eye 2003;17:571-8.

21 Carrasco JR, Penne RB. Optic nerve sheath meningiomas and advanced treatment options. Curr Opin Ophthalmol 2004;15:406-10.

22 Hood DC, Greenstein VC, Odel JG, et al. Visual field defects and multifocal visual evoked potentials: evidence of a linear relationship. Arch Ophthalmo 2002;120:1672-81.

\section{Combined triamcinolone acetonide injection and grid laser photocoagulation: a promising treatment for diffuse diabetic macular oedema?}

\section{Tomohiro lida}

$\mathrm{D}$ abetic macular oedema is a major cause of visual loss in patients with diabetes. The Early Treatment of Diabetic Retinopathy Study showed that focal laser photocoagulation reduced moderate visual loss in eyes with clinically significant macular oedema. ${ }^{1-3}$ The efficacy of grid photocoagulation for treatment of diffuse diabetic macular oedema was reported in the 1980s. ${ }^{4-6}$ Those studies reported resolution of macular oedema and stabilisation or improvement of visual acuity (VA). Eyes treated with conventional grid photocoagulation for diffuse macular oedema, however, developed progressively expanding laser scars that resulted in decreased vision, ${ }^{7}$ subretinal fibrosis $^{8}$ and visual field loss. ${ }^{69}$ Lee and Olk $^{10}$ reported that VA improved in $14.5 \%$ and was unchanged in $60.9 \%$ of eyes with diffuse macular oedema treated with grid laser photocoagulation. However, the VA decreased by three lines or more in $24.6 \%$ of eyes. The limited efficacy of grid laser photocoagulation for treatment of diffuse macular oedema prompted interest in modified methods of grid photocoagulation and other treatments such as steroid injections and pars plana vitrectomy.

In eyes with diffuse diabetic macular oedema, retinal opacification, macular swelling and fluid accumulation prevent the transmission of laser energy to the outer retina and the retinal pigment epithelium. Conventional grid laser photocoagulation, in which grey-white spots are applied around the fovea, causes intense retinal damage in the macular area. Innovations in photocoagulation technology have focused on improved laser instruments and laser techniques. Laser damage can be decreased by reducing the duration of laser exposure and by using subvisible clinical endpoint laser photocoagulation. ${ }^{11-13}$ Luttrull et al ${ }^{13}$ studied the visual and clinical outcomes of subthreshold diode micropulse laser photocoagulation in eyes with diabetic macular oedema. This method minimised retinal and choroidal damage and had a beneficial effect on VA and resolution of macular oedema.

Intravitreal injection of triamcinolone acetonide has been reported to improve VA and to reduce the macular thickness in eyes with diffuse diabetic macular oedema. ${ }^{14-18}$ However, the beneficial effect on vision and macular thickness does not persist in long term. Massin et a $l^{18}$ reported the results of a prospective controlled study of intravitreal triamcinolone acetonide, which showed that one intravitreal injection of triamcinolone acetonide reduced the macular thickening due to refractory diffuse diabetic macular oedema in the short term. All eyes that were injected with triamcinolone acetonide had a dramatic 